\title{
EL VINO EN LOS CONCILIOS HISPANOVISIGODOS: SU CONTEXTO SOCIOECONÓMICO Y CULTURAL
}

\author{
POR
}

\author{
Henar Gallego Franco \\ Universidad de Valladolid
}

\begin{abstract}
RESUMEN
Perfilamos la imagen socioeconómica y cultural del vino que encierran los concilios hispanovisigodos. Destacamos especialmente la vertiente religiosa de las referencias analizadas, que gira en tomo al papel del vino como «Sangre de Criston en la Eucaristía.
\end{abstract}

\section{AmStract}

Our research looks for the socioeconomic and cultural image of the wine culture in the Christian Councils of Visigothic Spain. Our sources' references to vineyards, grapes and wine specially have a religious side dealing with the role of wine as an offering in the altar at mass, and its sacred aspect as «Jesus' Blood».

Nuestro trabajo se propone descubrir y caracterizar la forma que adoptan las referencias al vino, en su vertiente de cultivo y de producto elaborado, en los textos conciliares hispanovisigodos, a través de un análisis detallado de los mismos, obteniendo un conjunto de conclusiones que quieren contribuir, en última instancia, al conocimiento y estudio de la vitivinicultura en la España visigoda, tanto en su perfil socioeconómico como religioso y cultural1'

1 Cfr. sobre el particular, L.A. Garcfa Moreno, «El paisaje rural y algunos problemas ganaderos en España durante la Antigiledad Tardía (s.V.VI d.C.)», Estudios en Homenaje a Don Claudio Sanchez Albomoz en sus 90 años, I, Anexos de Cuademos de Historia de España, 1983, 401-426; Idem, «La tecnologra rural en España durante la Antigiedad Tardía (ss.V-VII), MHA, III, 1979, 217-237; C. 
El conjunto de referencias vitivinícolas en los concilios hispanovisigodos se expresa en torno a los términos siguientes ${ }^{2}$ :

BOTRUM: Cfr. vinum $\mathrm{n}^{\circ} 6,7 \mathrm{~b}, 7 \mathrm{~d}$.

EBRIUS: Cfr. vinea $\mathbf{n}^{\circ} 2$.

FRUX LIQUIDA: Cfr. vinea $n^{\circ} 3$.

MERUM: Concilio de Braga II (572 d.C.), X (Ut presbyter post cibum non teneat missam pro mortuis): ... cognovimus quosdam praesbyteros in huius praessumtionis audaciam retineri, ut in missa mortuorum etiam post acceptum merum oblationem aussi sunt consecrare... ${ }^{3}$.

\section{SANGUIS CHRISTI}

1. Concilio de Lérida (546 d.C.), I (De his qui altario ministrant, ut a sanguine omni se abstineant): Di his clericis qui in obsessianis necessitate positi fuerint id statutum est, ut qui altario ministrant et Christi sanguinem tradunt...4.

2. Concilio de Toledo III ( 589 d.C.), (Item tractatus Chalcidonensis concilii): ...ut omnes ascrificii tempore ante conmunionem corporis Christi vel sanguinis.....et sic corda fide purificata ad Christi corpus et sanguinem percipiendum exhibeants.

3. Concilio de Toledo III (589 d.C.), II (Ut in omnibus ecclesiis die dominica sumbolum recitetur): ... et ad Christi corpus et sanguinem praelibandum pectora populonim fide purificata accedant.

Godoy/J. Vilella, «Consideracions sobre la vitivinicultura en època visigdtica», El vi a l'antiguitat. Economía, producció $i$ comerç al Mediterrani occidental (Actes I Col.loqui d'Arqueologia Romana, Badalona, 28 novembre-1 desembre 1985), Badalona, 1987, 438-443.

2 Para los Concilios hispanovisigodos empleamos la edición de J. Vives, Concilios visigoticos e hispanorromanos, Madrid, 1963. En nuestras menciones a la Lex Visigothorum (L.V.) o Liber Iudiciorum, y al Fuero Juzgo seguimos la edición: «Liber Iudicum aut Codex Wisigothorum», Los Códigos Españoles concordados y anotados, 12 vols., Madrid, La Publicidad, 1847 (1* edición), 18721873 (2" edición); «El Libro de los Jueces o Fuero Juzgo», Los Códigos Españoles concordados y anotados, 12 vols., Madrid, La Publicidad, 1847 ( $1^{\star}$ edición), 1872-1873 ( $2^{*}$ edición). Para facilitar la comprensión de las citas, las hacemos todas ellas dobles, ofreciendo junto con la referencia latina la versión en castellano o romance.

3 Concilio de Braga II, cánon $\mathrm{X}$ : «...toda vez que hemos conocido que algunos presbíteros por la necedad del error brotado recientemente o también conompidos todavía por el hedor de la vieja herejia priscilianista, incurren en el audaz atrevimiento de consagrar la oblación en la misa de difuntos aun después de haber sumido el vino...».

4 Concilio de Lérida, cánon I: «Acerca de los clérigos que se hallaren en los apuros de un asedio, se establece lo siguiente: Los que sirven en el altar y distribuyen la sangre de Cristo...».

5 Concilio de Toledo III, (Sobre el acuerdo del Concilio de Calcedonia): «... que todos durante el Sacrificio, antes de la comunión del cuerpo y sangre de Jesucristo..., y así, purificados sus corazones con la fe, se presenten a recibir el cuerpo y sangre de Jesucristo».

6 Concilio de Toledo III, cánon II: «... y los corazones del pueblo se acerquen purificados por la fe a recibir el cuerpo y sangre de Jesucristo».

Hispania, del Mediterráneo al Atlántico

Hispania Sacra 51 (1999) 
4. Concilio de Toledo IV (633 d.C.), XVIII (Quot post benedictionem populo datam communicare debeant sacerdotes): ... et tunc demum corporis et sanguinis Domini sacramentum summatur?.

5. Cfr. Vinum $7 \mathrm{~b}, 7 \mathrm{c}$.

6. Concilio de Braga III (675 d.C.), III (Ne sacerdos sine orario missam audeat celebrare): ...aut sacramentum corporis et sanguinis domini nostri lesu Christi...8.

7. Concilio de Toledo XII (681 d.C.), V (De quorumdam consuetudine sacerdotum foedissima, qui oblatis Deo per se sacrificiis non conmunicant): ...corporis et sanguinis domini nostri lesu Christi esse destiterit... totiens perceptioni corporis et sanguinis Christi se participem praebeats.

SANGUIS UVAE: Cfr. vinum $\mathrm{n}^{\circ} 4$.

TORCULAR: Cfr. vinum $n^{\circ} 4$.

UVA: Cfr. vinum $\mathrm{n}^{\circ} 7 \mathrm{a}, 7 \mathrm{~b}$.

VINDEMIA: Concilio de Toledo VII (646 d.C.), VI (De convicinis episcopis in urbe regia conmorandis): ...convicini Toletanae urbis episcopi, iuxta quod eiusdem pontificis admonitionem acceperint, singulis per annum mensibus in eadem urbem debeant conmorari, messivis tamen vel vindemialibus feriis relaxatis' ${ }^{10}$.

\section{VINEA}

1. Concilio de Toledo VIII ( 653 d.C.) (Lex edita in eodem concilio a Recesvinto principe namque glorioso): ... Similis quoque ordo de terris, vineis atque familis observetur, si sine scribturae textu tamtummodo coram testibus quaelibet facta fuerit definitio ${ }^{11_{m}}$.

2. Concilio de Toledo X (656 d.C.), VII (Ut nullus ex sacerdotibus, levitis vel ex catholicorum coetu audeat mancipia christiana iudaeis vel gentilibus venundari): Ecce pater familias plantavit vineam, id est eglesiam, et locavit eam agricolis, id est sacerdotibus. Quum ergo venerit dominus vineae quid faciet agricolis illis? Malos male perdet t vineam locabit allis agricolis, qui reddant ei fructus temporibus suis...»manducet autem et bibet cum ebriis, veniet dominus servi........12.

7 Concilio de Toledo IV, cánon XVIII: «...y entonces finalmente se sumirá el sacramento del cuerpo y sangre del Seffion.

8 Concilio de Braga III, cánon III: «...sea para recibir el sacramento del cuerpo y sangre de nuestro Seffor Jesucristo...\%.

9 Concilio de Toledo XII, cánon V: «...dejaren de participar del cuerpo y sangre de nuestro Sefor Jesucristo... otras tantas aparezca participando en la recepción del mismo Cuerpo y Sangres.

10 Concilio de Toledo VII, cánon VI: «...los obispos cercanos a la ciudad de Toledo, según aviso que recibirán del mismo metropolitano, deben residir en dicha ciudad un mes cada año, exceptuando los tiempos de la siega y de la vendimian.

11 Concilio de Toledo VIII, (Ley dada en este Concilio por el glorioso principe Recesvinto): «... La misma norma se guardará también acerca de las tierras, de las viñas y de los siervos, si se hizo alguna transmisión sin tftulo escrito, solamente delante de testigos».

12 Concilio de Toledo X, cánon VII: «He aquf que el padre de familia plantó la vifía, esto es, la Iglesia, y la arrendo a los labradores, esto es a los sacerdotes, y cuando viniere el Señor de la viña,

Hispania, del Mediterráneo al Atlántico Hispania Sacra 51 (1999) 
3. Concilio de Toledo XIII (683 d.C.) (In nomine Domini Flavius Ervigius rex omnibus privatis sive fiscalibus populis): Terras vero et vineas, quae pro eodem tributo quicumque supradictorum curam publicam agencium vobis privatis vel fiscalibus populis abstulit vel accepit, fruges aridas et liquidas exinde in praeteritis annis unusquisque exactor collegit in ratione ipsius tributi, hoc sibi imputet et terras ipsas vel vineas vobis de quorum iure abstultae sunt restituere non differat ${ }^{13}$.

VINIOLA: Concilio de Toledo II (527 d.C.), IV (Ut quidquid de iure ecclesiae elerici tenuerint, pos obitum eonum ad ecclesiam revertatur): Si quis sane clericorum agella vel viniolas in terras ecclesiae sibi fecisse probatur sustentandae vitae causa, usque ad diem obitus sui possideat 14.

VINUM:

1. Concilio de Tarragona (516 d.C.), III (Ut clerici si solidum praestiterint, sine usura recipiant): Si quis vero clericus solidum in necessitate praestiterit, ut hoc de vino vel fromento accipiat, quod mercandi causa tempore statuto decretum fuerit venundar ${ }^{15}$.

2. Concilio de Braga II (572 d.C.), LV (Quid in altario offerre oportet): Non oportet aliquid aliud in sanctuario offerre praeter panem et vinum et aquam... ${ }^{16}$.

3. Concilio de Braga II (572 d.C.), LXII: (De usuris vel negotionum lucris): ...aut ex quolibet negotio turpia lucra quaesierit aut per diversas species vini vel frugis... ${ }^{17}$.

4. Concilio de Sevilla II (619), XIII (De duobus in Christo naturas et una persona): ...Lex de passione corporis Christi sic dicit: «Lavabit in vino stolam suam et in sanguine uvae palleum suum....Quare rubrum est vestimentum tuum et indumentum tuum tamquam calcantium in torculari?

¿qué hará con aquellos labradores? Castigará a los malvados tertiblemente y arrendará la viña a otros labradores que le den frutos a sus tiempos.... ....coma pues y beba con los ebrios, vendrá el sef́or del siervo...»...».

13 Concilio de Toledo XIII (Edicto de Ervigio para la relajación del tributo): «Y las vifáas o tierras que por dicho tributo, alguno de los indicados que ocupan cargos públicos os arrebató o recibio de vosotros, particulares y siervos fiscales, los frutos secos y lifuidos que de ellas los años pasados cada uno de los recaudadores cosecho por razón del mismo tributo, se lo anotará a su favor, y no dilate el restituiros las tierras mismas y las viñas a vosotros, de cuyo patrimonio fueron arrebatadas».

14 Concilio de Toledo II, cánon IV: «Si algún clérigo se comprueba que se ha hecho algún huerto o alguna vī̄a en las tierras de la Iglesia para su propia sustentación, poséalo hasta el día de su muerte».

1s Concilio de Tarragona, III: «Si algún clérigo prestare en un caso de necesidad, dinero, reciba en vino o en trigo aquella cantidad, qque en término señalado para la devolución deba venderse para recobrar el dinero prestadon.

16 Concilio de Braga II, cánon LV: «No conviene ofrecer otra cosa en el santuario, sino pan, vino y agua, todo lo cual es bendecido en representación de Cristo...».

17 Concilio de Braga II, cánon LXII: «...u obtuviere algún provecho comprando y vendiendo diversas especies de vino, o de grano....

18 Concilio de Sevilla II, cánon XIII: «... Sobre la pasión de Cristo, la ley se expresa así: «Lavará en vino su estola y en mosto de uva su manton...» ... « ¿Por qué es rojo tu vestido y tus ropas, como las de los que pisan en el lagarm....

Hispania, del Mediterráneo al Atlántico

Hispania Sacra 51 (1999) 
5. Concilio de Toledo IV (633 d.C.), XI (De non cantando in Quadragesima Alleluia): ...sicut in illis $X L$ diebus, ceteris camibus abstinetur et a quibusdam etiam nec vinum bibitur ${ }^{19}$.

6. Concilio de Braga III ( 675 d.C.), preámbulo: Quidam enim in sacrificiis Domini relati sunt lac pro vino, pro vino botrum offerre, eucharistiam quoque vino madidam pro conplemento conmunionis credunt populis porrigendam..20.

7. Concilio de Braga III (675 d.C.), I (Ut repulsis omnibus opinionibus supprestitionum, panis tantum et vinum aqua permista in sacrificio offeratur $)^{21}$ :

a) ...lac pro vino in divinis sacrificiis dedicare, alios quoque intinctam eucharistiam populis pro conplemento comunionis porrigere. quosdam etiam non expressum vinum in sacramento domini calicis offerre sed oblatis uvis populis conmunicare...quod praeter panem et vinum aliud offerre non sinit ${ }^{22}$.

b) ...Nam quod de inexpresso botro, id est de uvarum granis populus conmunicatur...vino et aqua permixtus debet oferri; quia videmus in aqua populum intelligi in vino vero ostendi sanguinem Christi23.

c) ...Ergo quando in calice vino aqua miscitur.....quae copulatio et coniunctio aquae et vini.....Nam si vinum tantum quis offerat, sanguis Christi incipit esse sine nobis... ${ }^{24}$.

d) ...Ergo quando botrum solum offertur in quo vini tantum efficientia demonstratur.....non enim potest caliz Domini esse aquam solam aut vinum solum...25.

e) ...Et ideo nulli deinceps licitum erit aliud in sacrificiis divinis offerre nisi iuxta antiquorum sententias concilionum panem tantum et calicem vino et aqua permixtum... ${ }^{26}$.

8. Concilio de Toledo XVI (693 d.C.), VI (De integra oblata et ex studio praeparata in sacrificio offerenda): ...eamque super altare cum vino et aqua pro sacro libamine offerant...27.

19 Concilio de Toledo IV, cánon XI: «...del mismo modo que en la cuaresma, se abstendrán de las restantes carnes, $y$ algunos no beberán tampoco vinon.

20 Concilio de Braga III (preámbulo): «Pues algunos han sido acusados que en el sacrificio del Señor ofrecen leche en lugar de vino o también en vez del vino ofrecen un racimo de uvas, y creen tambien que debe darse al pueblo la Eucaristía empapada en vino, como complemento de la comunión...,

21 Concilio de Braga III, cánon I: «Que desechando todas las opiniones superticiosas, se ofrezca en el sacrificio solamente pan y vino mezclado con aguax.

22 Concilio de Braga III, cánon I: «...presentan en los divinos sacrificios leche en lugar de vino, y otros también dan al pueblo como complemento de la comunión, la eucaristía mojada en vino; y otros también no ofrecen en el Sacramento del Cáliz del Señor vino exprimido, sino que comulgan al pueblo con las ofrendas de uvas... que no permite ofrecer otra cosa fuera del pan y del vinon

23 Concilio de Braga III, cánon I: «Y respecto a dar la comunión al pueblo con un racimo no exprimido, esto es, con los granos de las uvas... debe ser ofrecido mezclados el vino y el agua, porque vemos que por el agua se representa el pueblo y por el vino la sangre de Cristo».

24 Concilio de Braga III, ćánon I: «Ast pues cuando se mezcla el agua y el vino... la cual unión y junta del agua y del vino......pues si alguno ofrece solamente vino la sangre de Cristo comienza a existir sin nosotros...."

${ }^{25}$ Concilio de Braga III, cánon I: «...Luego cuando se ofrece solamente el racimo de uvas, en el cual tan s6́lo aparece la existencia del vino...pues no puede el cáliz del Señor consistir en agua sola o en vino solo...”

26 Concilio de Braga III, cánon I: «...Y por lo tanto, de ahora en adelante a nadie le será lícito ofrecer otra cosa en los divinos sacrificios, sino solamente el paz y el cáliz mezclado de vino y agua..."

27 Concilio de Toledo XVI, cánon VI: «...y la ofrecen sobre el altar con el vino y el agua...» 
El mayor número de citas se refieren al vino como tal (vinum), con variantes como merum (vino puro) o frux liquida (fruto líquido). También se menciona en una ocasión al mosto o zumo de uva (sanguis uvae). La mayor parte de las referencias al vino o sus variantes tienen un contenido estrictamente religioso, que toma en ocasiones la forma de citas bíblicas ${ }^{28}$, pero que se centran sobre todo en su papel como ofrenda eucarística en el altar en el transcurso de la misa ${ }^{29}$. La importancia de la vertiente religiosa del término vinum viene reforzada por el hecho de que el conjunto de referencias al vino como sangre de Cristo (sangui Christi) es el siguiente en importancia numérica en nuestro estudio. En este aspecto, destaca la condena de prácticas tales como sustituir en el altar el vino por leche, o por un racimo de uvas sin exprimir, que debían estar difundidas en algunas comunidades cristianas hispanovisigodas del último tercio del s.VI y durante el s.VII d.C., quizá en aquellas que por su ubicación carecían de su propia producción de vino, o aquellas especialmente pobres, a las que no era fácil proveerse de vino de cierta calidad para la Eucaristía ${ }^{30}$.

El cánon III del Concilio de Tarragona de comienzos del s.VI d.C. contempla la posibilidad de que el vino se convierta en un objeto de cambio en los préstamos, evidenciando su gran difusión y su valor como producto de consumo. Del mismo modo, Ias fuentes jurídicas de la España Visigoda contemplan al vino como un producto preciado, de consumo generalizado, y con un valor en sí mismo que le hace objeto de préstamo y usura ${ }^{31}$. El Concilio de Braga II del año 572 d.C. atestigua en su cánon $X$ el consumo de vino, en este caso de vino puro o merum, por parte de los ministros de la Iglesia ${ }^{32}$. El cánon XI del Concilio de Toledo IV (633 d.C.) recoge la prohibición general de su consumo en la Cuaresma, al igual que la carne, en sintonía con la pena de penitencia para obispos y señores que recoge la Lex Visigothorum, y que implica abstenerse de

\footnotetext{
28 Concilio de Sevilla II, canon XIII; cfr. Génesis, 49,11.

29 Concilio de Braga II, cánon LV; Concilio de Braga III (preámbulo); Concilio de Braga, III, cánon I; Concilio de Toledo, XVI, cánon VI.

30 C. Godoy/J. Vilella, «Consideracions sobre la vitivinicultura en època visigotica», El vi a l'antiguitat. Economia, producció $i$ comerç al Mediterrani occidental (Actes I Colloqui d'Arqueologia Romana, Badalona, 28 novembre-I desembre 1985), Badalona, 1987, 441.

${ }^{31}$ L. V., Libro V, título V, ley IX.

32 A pesar de que existen testimonios literarios de condena sobre los Visigodos, por su abuso del vino, cfr. Prospero, Carmen de Prov., v. 903-906 (PL, 51, 637- 415 d.C.), e incluso sobre los hispanos, cfr. MGH, Chronmin., It, p. 390, no hay en los textos de los concilios hispanovisigodos condenas explicitas al consumo abusivo del vino. Cfr., en cambio, M.B. Lancon, «Vinolentia: L'ivrognerie en Gaule à la fin de l'Antiquité d'après les sources littéraires», Archeologie de la vigne et du vin (Actas du Colloque 28-29 mai 1988), Paris, 1990, 158-159, recoge abundantes testimonios literarios sobre el escandaloso comportamiento de los obispos y grupos eclesiásticos, así como de la aristocracia gala en relación al abuso de vino, fruto de condenas no sólo en los sermones sino en algún cánon conciliar.
}

Hispania, del Mediteráneo al Atlántico Hispania Sacra 51 (1999) 
beber vino y comer carne, consumiendo sólo pan y agua ${ }^{33}$. Parece, pues, que el vino era consumido por una gran parte de la población, pero seguramente con fuertes diferencias en cuanto a la cantidad y sobre todo la calidad del producto consumido. El vino de calidad debía formar parte de la dieta habitual de grupos sociales privilegiados, y era signo indudable de bienestar y lujo ${ }^{34}$.

A pesar de que es bien conocida en época romana, a través de las fuentes literarias ${ }^{35}$ y arqueológicas ${ }^{36}$, la existencia de diferentes variedades de vinos hispanos, algunas de las cuales alcanzaron gran fama en el Imperio, los textos conciliares hispanovisigodos no se hacen eco de esta posibilidad, a no ser por el cánon LXII del Concilio de Braga II (572 d.C.), donde se alude claramente a la existencia de distintas clases de vinos, aunque sin precisar más al respecto ${ }^{37}$.

Después de vinum y sanguis Christi, el término vitivinícola más frecuente en los concilios hispanovisigodos es el de viña (vinea, viniola). El contenido religioso de su contexto de aparición, mucho menor que en las referencias hasta ahora analizadas, se relaciona con los textos evangélicos que ven en la

33 L.V., Libro IX, título I, ley XXI.

34 San Isidoro, Etym., XX, 3; cfr. C. Godoy/J. Vilella, «Consideracions sobre la vitivinicultura en epoca visigdtica», El vi a l'antiguitat. Economí, produccí́ $i$ comerc al Mediterrani occidental (Actes I Col.loqui d'Arqueologia Romana, Badalona, 28 novembre-1 desembre 1985), Badalona, 1987, 442; Cfr. M.B. Lançon, «Vinolentia: L'ivrognerie en Gaule a la fin de l'Antiquité d'après les sources littéraires", Archéologie de la vigne et du vin (Actas du Colloque 28-29 mai 1988), Paris, 1990, 158, donde el consumo y el abuso del vino aparece extendido a todas las categorías de la población, de acuerdo con las fuentes literarias tardías.

35 Plinio, N.H., XIV,71; Marcial, Epigram, I, 26 y XIII,118; Silio Itálico, III, 369: se citan los vinos layetanos, lauronenses, baléricos, y los de Tarraco.

36 Las marcas de ánforas del monte Testaccio en Roma comprueban la exportación de vinos hispanos de Tarraco y Lauro; cfr. CIL XIV, 4577, 4578; CIL XV 2632; A. Tchernia, «Les amphores vinaires de Tarraconaise et leur exportation au début de l'Empire», AEA, 44, 1971, 38-85; VV.AA., El vi a l'antiguitat. Economia, producció $i$ comerç al Mediterrani occidental (Actes I Col.loqui d'Arqueologia Romana, Badalona, 28 novembre-1 desembre 1985), Badalona, 1987; VV.AA., Archeologie de la vigne et du vin (Actas du Colloque 28-29 mai 1988), Paris, 1990; P. Sáez Fernández, Agricultura romana de la Bética, Sevilla, 1987, 1-74; J. Miro, «Les estampilles sobre àmfores catalanes. Una aportació al coneixement del comerç del vi del Conventus Tamraconensis a finals de la Republica i principis de l'Imperi”, Fonaments, 7, 1988, 243-263; V. Revilla, Producción cerámica, viticultura y propiedad nural en Hispania Tarraconensis (siglos I a.C.-III d.C.), Barcelona, 1995, 149-155; O. Olesti, El territori del Maresme en època republicana (s.II-I a.C.). Estudi d'Arqueomorfologia i Historia, Mataro, 1995, 74-75; M.J. Pena/A. Barreda, «Productores de vino del nordeste de la Tarraconense. Estudio de algunos nomina sobre ánforas Laietana 1 (= Tarraconense 1), Faventia, 19/2, 1997, 51-73. Sobre el papel del vino en la sociedad romana y las diferentes variedades, cfr. C. Real Tonres, «El vino como alimento y medicina en ta sociedad romanas, Fortunatae, 3, 1992, 305-314.

37 San Isidoro, Etym. XX, 3, diferencia tipos de vino en relación a su calidad. Tampoco se menciona explícitamente en la Lex Visigothonum la existencia de diferentes variedades de vino, por calidad u origen, pero la aparición puntual del término «vinos», en plural, parece sugerir que, de hecho, éstas eran una realidad, cfr. $L V$, Libro XII, tínulo II, ley VII = Fuero Juzgo, Libro XII, tínulo IV, ley VII. 
viña la imagen de la Iglesia de $\operatorname{Dios}^{38}$. Sin embargo, predomina la alusión a la viña como parte del patrimonio de los individuos (tierras, viñas y siervos), como una de las formas que puede presentar la propiedad rural, distinta de otras expresadas mediante otros términos, como «huertos» (agella), o el más general «tierras» (terrae). Como tal, se recogen y regulan aquellos aspectos sobre su propiedad, donación y enajenación en los que pueden verse implicados la Iglesia y sus miembros. Así, una vertiente de la problemática generada por el cultivo de viñas en tierras ajenas ${ }^{39}$ se expresa en el cánon IV del Concilio de Toledo II (año 527 d.C.), que recoge la posibilidad de que los clérigos cultiven viñas en las tierras de la Iglesia para su propio sustento, probablemente para su consumo personal y para estar provistos de vino para la Eucaristía. También en el Concilio de Toledo VIII del año 653, que recoge la ley de Recesvinto en relación a las donaciones a los príncipes, de nuevo aparecen las viñas como objeto de donación, al ser un cultivo muy extendido, parte frecuente del patrimonio de los individuos. Por la misma razón, tanto las viñas como el vino son objeto de obligaciones fiscales, y se constituyen en elemento de pago de los tributos exigidos por reyes y señores, como se refleja en las disposiciones del edicto de Ervigio para la relajación del tributo, que se recoge en el Concilio de Toledo XIII ( 683 d.C.).

Estas referencias analizadas evidencian la gran extensión del cultivo de la vid en la España Visigoda a través del predominio del policultivo. La frecuencia del policultivo en el mundo rural se corrobora igualmente a través de la Lex Visigothorum, que abunda en referencias a la viña como forma de cultivo individualizada, pero a menudo asociada a otras, y omnipresente en el paisaje rural hispano ${ }^{40}$, y a través de los testimonios arqueológicos ${ }^{41}$. En este sistema de

38 Concilio de Toledo, X, cánon VII; cfr. Mateo 24, 49; Lucas, 12, 45.

39 Este aspecto también es objeto de regulación, con una casuristica más variada, en la Lex Visigothorum: L.V., Libro X, título I, ley VI; $L . V$, Libro X, título I, ley VII.

40 L.V., Libro X, título I, ley XIX: «Si quis terram, vineam aut aliquam rem aliam pro decimis.... (Fuero Juzgo, Libro X, título I, ley XIX: «Si algun omne tiene de otro tierra 6 vinna arrendada.....»); L.V., Libro VI, titulo II, ley III: «...in vineis messibusque...» (Fuero Juzgo, Libro VI, título II, ley IV: *...fazen caer la piedra en las vinnas 6 en las mieses...»); $L . V .$, Libro VII, título III, ley X: «De animalibus voluntarie in messem, vel vineas missis: ...in vineam vel messem...» (Fuero Juzgo, Libro VII, título III, ley X: «De los que meten ganados en mieses aienas, 6 en vinnas: ...en miesse aiena 6 en vinna...»); $L V$., Libro VII, título III, ley XI: «...vineam vel messem everterint alienam...tamtum vineae vel agri ctm frugibus...agrum aut vineam..agri vel vineae...» (Fuero Juzgo, Libro VHI, título III, ley XI: «... miesse aiena 6 vinna...otra tanta de miesse, 6 de la vinna...de la miesse 6 de la vinna...otra tal mies, 6 otra tal vinna...»); $L V$., Libro VIII, título III, ley IX: «...cum frugibus vineam, pratum vel pascua...per vineam aut messem...» (Fuero Juzgo, Libro VIII, título III, ley IX: «...vinna 6 prado en logar en que a fructo ó pasto... por la vinna, ó por la miesse...»); $L$.V., Libro VI, título II, ley IV: «...in agris, vel vineis diversisque arboribus...» (Fuero Juzgo, Libro VI, título II, ley V: ...en vinnas, 6 en miesses, 6 en campos.....»); $L . V$., Libro VII, título II, ley III: «...et messis, aut area vel vinea, aut domus... (Fuero Juzgo, Libro VIII, título II, ley III: «... mies, 6 vinna, 6 casa, 6 vergel...»);

Hispania, del Mediterráneo al Atlántico

Hispania Sacra 51 (1999) 
policultivo, que tiende a asegurar la continuidad del trabajo y el autoabastecimiento de las comunidades rurales, la viña ocupa un lugar fundamental. Del mismo modo, siempre que se enumeran en la Lex Visigothorum los bienes que pueden formar parte del patrimonio de los individuos encontramos la referencia explícita a las viñas ${ }^{42}$, que, como cualquier otra propiedad, pueden ser objeto de donaciones, ventas, $o$ arrendamientos ${ }^{43}$.

No existen, por otro lado, en los textos conciliares referencias a las labores del cultivo del viñedo o a los diferentes trabajos y etapas de la fabricación del vino, y tampoco a los útiles o instrumentos necesarios en todos estos proce-

L.V., Libro VIII, título III, ley XIII: «...in vinea, messe, prato vel horto...campi vel vineae sive prati aut messis..." (Fuero Juzgo, Libro VIII, tutulo III, ley XIII: «... en su mies, 6 en su vinna, 6 en su huerto, 6 en su prado...de la vinna, é del campo, 6 de la mies, é del prado....n); $L V$., Libro VIII, título III, ley XV: «De animalibus in vinea, messe vet prato praeventis: Si quis in vineae sua, messe prator vel horto...» (Fuero Juzgo, Libro VII, título III, ley XV: «De los que fallan el ganado en las vinnas, ó en las mieses: Todo omne que fallar en su vinna, 6 en su miese, 6 en su prado, 6 en su huerto.... $)$; L.V., Libro VII, título IV, ley XXII: "Si quis sudes in vinea posuerif, sive in campo ..." (Fuero Juzgo, Libro VIII, título IV, ley XXII: «Si algun omne pone armadijas en su viña, o en su campo...»); $L V$., Libro VIII, título IV, ley XXV: «...messem aut vineam vel prafum...» (Fuero Juzgo, Libro VIII, tifulo IV, ley XXV: «...alguna mies, 6 vinna, $\delta$ prado.... ); $L . V$., Libro X, título I, ley VI: «...aut vineam plantaverit, sive olveta, hortum vel pomaria...» (Fuero Juzgo, Libro X, título I, ley VI: «...6 vinna, $\delta$ huerta, 6 olivedos, $\delta$ pumares.... $)$.

41 C. Godoy/J. Vilella, «Consideracions sobre la vitivinicultura en epoca visigdtica», El vi a l'antiguitat. Economía, producció $i$ comerç al Mediterrani occidental (Actes I Col.loqui d'Arqueologia Romana, Badalona, 28 novembre-1 desembre 1985), Badalona, 1987, 440.

${ }_{42}^{2}$ L.V., Libro II, título I, ley V: «...de terris, vineis, atque familiis...» (Fuero Juzgo, Libro II, titulo I, ley V: «... de las tierras et de las vinnas, é de los siervos...»); $L V$., Libro IV, título V, ley III: «De his quae parentes tempore nuptianum dederint filis suis: ...quod utique commodantibus erit reddendum, in mancipiis, terris, vineis, aedificiis, vestimentis atque ornamentis fuerit a parentibus..." (Fuero Juzgo, Libro IV, título V, ley III: «De las cosas que dan los padres en las bodas:... si alguna cosa recibieren los esposados de los padres en tiempo de sus bodas en siervos, 6 en vinnas, 6 en tierras, 6 en casas, 6 en vestidos, 6 en otros omamientos...»); $L V$., Libro V, título IV, ley VI: «Si dicat quis rem suam vili pretio vendidisse: Venditionis haec forma servetur, ut seu res aliquae, sive terrae, vel mancipia, vel quodlibat animalium genus venditur..." (Fuero Juzgo, Libro V, título IV, ley VII: «Si alguno dize que vende su cosa por menos precio que non valí: Si alguno omne vende algunas casas, $\sigma$ tierras, $\sigma$ vinnas, $\delta$ siervos, ó siervas, $\sigma$ animalias, 6 otras cosas... $) ; L V$., Libro V, tftulo IV, ley XIII: «...domum, agrem, vel vineamseu mancipium..." (Fuero Juzgo, Libro V, título IV, ley XIV: «...casa, o vinna, 6 siervo, 6 posession....); $L V$., Libro V, tftulo IV, ley XIX, «,... in mancipiis, terris, vineis domibusque perceperit... $\gg$ (Fuero Juzgo, Libro V, tínlo IV, ley XX: «...en tierras 6 en vinnas, 6 en casas, 6 en siervos...n); $L, V$., Libro XII, título II, ley XVIII: «...et tam mancipia, quam aedificia, terras, vineas, atque etiam oliveta, vel alias quascumque res immobiles quas a christianis venditionis...» (Fuero Juzgo, Libro XII, título II, ley XVIII: «... et siervos, et casas, et tierras, et vinnas, et olivares, et toda cosa, et heredat que ayan comprada de los cristianos...)».

43 Sobre las donaciones de viffas, cfr. $L V$., Libro II, título I, ley V; $L V$., Libro IV, títalo V, ley III. Sobre las ventas de vifias cfr. $L V$., Libro V, tf́ulo IV, ley VII; $L V$., Libro V, título IV, ley XIII; $L V$, Libro V, tútulo IV, ley XIX. Sobre los anendamientos de vinas, cvfr. $L V$., Libro X, t́t́lo I, ley XIX. 
$\operatorname{sos}^{44}$. Otros términos vitivinícolas recogidos en nuestro estudio, como racimo (botrum), uvas (uvae), mosto (sanguis uvae), lagar (torcular) y borrachos (ebrii), se ubican de nuevo en un contexto religioso, bien en la mención de pasajes de las Sagradas Escrituras ${ }^{45}$, o en relación a la Eucaristía ${ }^{46}$, desprovistos por tanto de un contenido socioeconómico y cultural en relación con la sociedad del momento ${ }^{47}$. Mayor interés presenta la única mención constatada a la vendimia (vindemia). El cánon VI del Concilio de Toledo VII (646 d.C.) manifiesta, en su regulación de las estancias de los obispos de las comunidades cercanas a Toledo en esta capital, el respeto al período de vendimia, igual que al de siega. El mismo papel relevante de los períodos de vendimia y siega en la vida de la comunidad se pone de manifiesto en la Lex Visigothorum o Liber Iudiciorum ${ }^{48}$. El estudio comparado de los textos conciliares y jurídicos muestra la importancia del ciclo agrario en las festividades anuales, así como la importacia que la vendimia tiene en la vida de una comunidad, en cuyas tareas se vuelcan todas las fuerzas de la misma, y cuya intensidad desaconseja, en este caso, la ausencia del obispo de su sede. Siega y vendimia se recogen como ciclos agrícolas maestros que marcan el ritmo de vida de los hombres a lo largo del año, y que modifican durante un tiempo el normal desarrollo de otras actividades, como las judiciales o los deplazamientos de las jerarquías eclesiásticas.

En conclusion, el análisis de los términos vitivinícolas rastreados en los textos de los Concilios hispanovisigodos pone de manifiesto la extensión notable del viñedo y del consumo del vino en la España Visigoda, así como la importancia socioeconómica y cultural de la vitivinicultura. El término más frecuentemente mencionado es el de «vino» (vinum), con algunas variantes que se refieren al «mosto» (sanguis uvae), al «vino puro» (merum) o la existencia, sin precisar, de «distintas especies de vino» (diversas species vini). La referencia al vino está igualmente implícita en expresiones metafóricas como «fruto

44 Sobre las técnicas romanas cfr. M. C. Amouretti, «La viticulture antique: contraintes et choix techniques», Revue des Etudes Anciennes, XC 1-2, 1988, 5-17.

45 Concilio de Toledo X, cánon VII; cfr. Isaáas, 63,3. Concilio de Sevilla II, XIII; cfr. Génesis, 49, 11.

46 Concilio de Braga III, preámbulo y cánon I.

47 Sobre la ebriedad en la Antigüedad Tardía, cfr. M.B. Lançon, «Vinolentia: L'ivrognerie en Gaule à la fin de l'Antiquité d'après les sources littéraires", Archéologie de la vigne et du vin (Actas du Colloque 28-29 mai 1988), Paris, 1990, 155-161, donde incide en el exceso en el consumo de vino como un tópico referido a los distintos pueblos bárbaros de Europa occidental y al mundo nural entre los siglos IV y VI d.C., imagen que se opone a la sobriedad de los nuevos valores cristianos.

48 El Código establece la duración del período de la vendimia, del 15 de septiembre al 15 de octubre, incluyendole entre las fiestas del calendario anual. En relación al ámbito jurfdico y judicial, se establece claramente que no deben celebrarse pleitos y juicios durante la vendimia, y que las comparecencias de aquellos que ya estén iniciados deben posponerse hasta que transcurre este periodo. Cfr. $L_{n} V$., Libro II, título I, ley X = Fuero Juzgo, Libro II, t́tulo L, ley X. 
líquido» (frux liquida), y sobre todo en la de «Sangre de Cristo» (Sanguis Christi). Desde el punto de vista socioeconómico, el vino aparece como un producto muy extendido y de indudable valor, lo que le puede convertir en objeto de préstamo, usura o del pago de impuestos. Su consumo, sin embargo, siempre tiene algo de superfluo o caprichoso para las autoridades eclesiásticas, por lo que debe ser eliminado de la dieta en caso de Cuaresma o de penitencia. Otro grupo importante de referencias se refieren a la viña (vinea, viniola). Éstas presentan el viñedo como una forma diferenciada de cultivo y propiedad rural, parte importante del extendido sistema de policultivo.

Desde el punto de vista cultural, en los textos conciliares la vitivinicultura encuentra su forma de expresión más potente a través del fenómeno religioso. Así, hemos constatado la vinculación de la mayoría de los términos analizados con el ámbito religioso, lo que, por otro lado, se adecúa con el propio carácter de las fuentes estudiadas. Emerge, así, poderosamente el respeto al vino a través de su vertiente religiosa como parte esencial de la ofrenda eucarística y como sangre de Cristo tras su transformación en la misma. Sin duda los fuertes lazos de unión entre el vino y el Cristianismo contribuyeron al arraigo profundo y al respeto de la cultura del vino en el territorio hispano ${ }^{49}$.

49 La importancia de la vitivinicultura en la España Visigoda se explica aś, primero por la continuidad de la dieta romano-mediterránea, así como por el uso litúrgico y medicinal del vino; Cfr. C. Godoy/J. Vilella, "Consideracions sobre la vitivinicultura en època visigòtica», El vi a l'antiguitat. Economí, producció i comerç al Mediterrani occidental (Actes I Collogui d'Arqueologia Romana, Badalona, 28 novembre-1 desembre 1985), Badalona, 1987, 439; M.B. Lançon, «Vinolentia: L'ivrognerie en Gaule à la fin de l'Antiquité d'après les sources littéraires», Archéologie de la vigne et du vin (Actas du Colloque 28-29 mai 1988), Paris, 1990, 158.

Hispania del Mediterráneo al Atlántico Hispania Sacra 51 (1999) 